\title{
Position Paper: The Role and Use of Educational Theory in Formulating Language Policy
}

Jim Cummins

Although most politicians and policy-makers realize the necessity to pay lip-service to research in formulating educational policy and programs insofar as all initiatives must be justified as being "in the best interests of children", it is not difficult to see that research and theory are coherently applied to policy only in situations where there is a relatively high degree of consensus in regard to both the societal and educational goals of the policy debates relating to language and education. Two of these debates are bilingual education programs in the United States and French immersion programs in Canada.

I shall argue that in both these cases, the sociological context of the debate, i.e. the power relations between dominant and subordinate groups in the society, plays a major role in determining the choice of issues to investigate, the conduct of the research, the interpretation of findings, and the relevance they assume for policy. In short, the relation between research, theory and policy can be understood only in the context of what Paulston (1980) terms a "conflict" paradigm where group conflicts over values, resources, and power are explictly taken into account.

\section{The Relation Between Research, Theory and Policy}

In the United States, controversy has raged for almost twenty years on appropriate ways of educating minority language children. Bilingual programs were mandated by the Office of Civil Rights in their interpretation of the Supreme Court's Lau v. Nichols decision in 1974, but there still exists no consensus regarding the effectiveness of such programs and many educators and policy-makers have expressed fears that bilingual education is "unAmerican" and will balkanize the country.

A major reason why many policy-makers and educators in the United States regard the research basis for bilingual education as minimal or even non-existent is that they have failed to realize that data or "facts" from bilingual programs become interpretable for policy purposes only within the context of a coherent theory. It is the theory rather than the individual research findings that permits the generation of predictions about pro- 
gram outcomes under different conditions. Research findings themselves cannot be directly applied across contexts. For example, the fact that kindergarten and grade 1 Punjabi-background students in a bilingual program in Bradford, England, learned English just as successfully as a control group in a traditional English-only program (Rees 1981) tells us very little about what might happen in the case of Greek-background students in Bradford or Hispanic students in the United States. Similarly, the findings of French immersion programs for majority students in Canada cannot be directly applied to policy-decisions regarding programs for minority students in the United States. Yet clearly the accumulation of research findings does have relevance for policy. This relevance is achieved by means of the integration of the findings within a coherent theory from which predictions regarding program outcomes under different conditions can be generated.

In short, although research findings cannot be applied directly across contexts, theories are almost by definition applicable across contexts in that the validity of any theoretical principle is assessed precisely by how well it can account for the research findings in a variety of contexts. If a theory cannot account for a particular set of research findings, then it is an inadequate or incomplete theory.

\section{Theory and the U.S. Bilingual Education Policy Debate}

Two opposing theoretical assumptions have dominated the U.S. policy debate regarding the effectiveness of bilingual education in promoting minority students' academic achievement. These assumptions are essentially hypotheses regarding the causes of minority students' academic failure and each is associated with a particular form of educational intervention designed to reverse this failure. In support of transitional bilingual education where some initial instruction is given in students' first language (L1), it is argued that students cannot learn in a language they do not understand; thus, a home-school language switch will almost inevitably result in academic retardation unless initial content is taught through $\mathrm{L} 1$ while students are acquiring English. In other words, minority students" academic difficulties are attributed to a "linguistic mismatch" between home and school.

The opposing argument is that if minority students are deficient in English, then they need as much exposure to English as possible. Students' academic difficulties are attributed to insufficient exposure to English in the home and environment. Thus, bilingual programs which reduce this exposure to English even further appear illogical and counterproductive in that they seem to imply that less exposure to English will lead to more English achievement. The following passage from a New 
York Times editorial (October 10, 1981) is typical:

The Department of Education is anlyzing new evidence that expensive bilingual education programs don't work . . Teaching nonEnglish speaking children in their native language during much of their school day constructs a roadblock on their journey into English. A language is best learned through immersion in it, particularly by children . . . Neither society nor its children will be well served if bilingualism continues to be used to keep thousands of children from quickly learning the one language needed to succeed in America.

Viewed as theoretical principles from which predictions regarding program outcomes can be derived, the "linguistic mismatch" and "insufficient exposure" hypotheses are each patently inadequate. The former is refuted by the French immersion data which clearly demonstrate that for English-background students in Canada a home-school language switch results in no academic retardation. The success of a considerable number of minority students under home-school language switch conditions similarly refutes the linguistic mismatch hypothesis.

The "insufficient exposure" hypothesis fares no better. Virtually every bilingual program that has ever been evaluated (including French immersion programs) shows that students instructed through a minority language for all or part of the school day perform, over time, at least as well in the majority language (e.g. French in North America) as students instructed exclusively through the majority language.

The fact that two such patently inadequate theoretical assumptions have dominated the bilingual education policy debate in the United States illustrates the power of politics over logic. It also shows the necessity of integrating theory explicitly into the decision-making process. One possible decision-making sequence or "flow-chart" with respect to bilingual education policy in different contexts is presented in the next section.

\section{A Framework for Theoretically-Based Decision-Making in Educational Language Planning}

Any language planning process will first identify a particular problem (e.g. underachievement of certain groups of minority students) and then focus upon solutions to this problem. These solutions will involve either explicit or implicit hypotheses about the causes of the problem (e.g. "linguistic mismatch" or "insufficient exposure" to the school language) followed by the identification of alternative goals and means to resolve the problem. An idealized (and undoubtedly over-simplified) sequence for this type of decision-making is presented in Figure 1. 
Figure 1

Sequence for Analysing Language Problems in Education

1. Examine perceived problems

2. Generate hypotheses about causes in light of theory and research

3. Plan solutions to problems: identify goals and means

4. Implement interventions to resolve problem

5. Monitor (or initiate) research relevant to theory about causes of problem

6. Evaluate success or failure of intervention

7. Communicate intervention results to policy-makers, educators and public

The decision-making process can be illustrated by comparing the highly successful implementation of French immersion programs in Canada during the late 1960's and 1970's with the generally much less successful implementation of bilingual programs for linguistic minority students in the United States during the same period. In both situations the general perceived problem was similar, namely, lack of student proficiency in a socially-valued language (French in Canada and English in the United States). However, in Canada the "clients" of immersion programs were members of the dominant group whereas bilingual programs in the United States were designed to remediate presumed deficiencies of subordinate groups.

With respect to causes of the problem, sociopolitical considerations have been largely ignored in the policy debates. However, as Paulston (1980) has frequently pointed out, the major causes of most language planning problems are sociopolitical in nature with psychoeducational and linguistic factors acting as intervening variables. By the same token, the effects of educational interventions aimed at resolving such problems can usually be understood only in terms of their interaction with sociopolitical factors. In other words, interventions based on linguistic or psychoeducational hypotheses in isolation from the context of inter-ethnic group relations will frequently fail to produce the predicted outcomes.

In the Canadian situation, the writings of the Montreal neurosurgeon Wilbur Penfield were influential. Penfield (1965) had speculated (partly on the basis of neuropsychological evidence) that there is an optimal prepubertal period for acquiring an L2 and our language learning capacity declines after this period; he also suggested that second languages should be taught by what he called "the mother's method" by which he meant used as a medium of communication in the classroom to permit 
children to acquire their L2 in much the same way as they acquired their L1. It is not difficult to see how these hypotheses gave rise to early French immersion programs.

In the United States situation as discussed previously, linguistic hypotheses ("linguistic mismatch" and "insufficient exposure") have tended to dominate the debate regarding causes of linguistic minority students' underachievement. The linguistic mismatch hypothesis tends to give rise to "quick-exit" transitional bilingual programs, whereas the insufficient exposure hypothesis justifies English-only programs, often with some English-as-a-second-language (ESL) instruction. It is at this point that the planning process begins to break down in the United States context since neither of these hypotheses is consistent with the research data. Thus, it is not surprising that programs implemented on the basis of these hypotheses have not been particularly successful.

At the third stage, the goals and means of immersion programs were clearly defined and non-problematic. They served the interests of the dominant group and there was general consensus regarding goals and means. This, however, was not the case with bilingual education in the United States. All parties agreed with the goal of improved English academic skills but many minority advocates also desired bilingual programs to further the development of a pluralistic society through an emphasis on native culture and language maintenance. This goal was vehemently resisted by many "mainstream" educators and policymakers. During the late 1970 's, the suspicion grew that bilingual programs were in reality intended only to promote Hispanic political and economic goals (even Hispanic separatism following the Quebec model) under the guise of developing students' English language skills. Thus, lack of consensus on goals and means compounded difficulties created by questionable psychoeducational assumptions used to justify bilingual education.

Problems of implementation followed naturally from the confused psychoeducational rationale and disputed goals of bilingual education in the United States. An enormous variety of programs results, ranging from considerable use of $\mathrm{L} 1$ in the early grades to virtually no use of L1. Some programs appeared to work extremely well, others much less so. By contrast, immersion programs started off on a very small scale with the St. Lambert program in the Montreal area (Lambert \& Tucker 1972) and a team of researchers monitored the progress of students through the grades. No further implementation was carried out until the initial results of this evaluation were available.

In both the United States and Canadian contexts, a considerable amount of evaluative research was carried out to assess the effects of the 
bilingual programs. In the case of the immersion programs, the initial St. Lambert program was thoroughly evaluated over a period of seven years and students were also followed through high school and beyond. As the immersion program spread to other areas, large-scale evaluations were also carried out to assess the consistency of findings with those of the St. Lambert program (e.g. Swain \& Lapkin 1982). One of the reasons for this was continued doubts among educators and parents that children could spend so much instructional time through French with no negative consequences for their English academic skills. Although some problematic issues have emerged (Burns and Olson 1981; Cummins 1984), the weight of research evidence has overwhelmingly confirmed the initial St. Lambert findings. Over time, theoretical principles emerged which could account for the absence of negative effects on English academic skills (Lambert and Tucker 1972; Cummins 1984). For example, the "interdependence principle" appears to account for the data from both French immersion programs and bilingual programs for minority students:

To the extent that instruction in $\mathrm{Lx}$ is effective in promoting proficiency in Lx, transfer of this proficiency to Ly will occur provided there is adequate exposure to Ly (either in school or environment) and adequate motivation to learn Ly.

It is interesting to note that, with respect to the initial theoretical assumptions underlying immersion, the research has refuted Penfield's hypothesis of an optimal age for language learning in that students in late immersion programs (usually beginning at grade 7 - aged 12-13) also succeed very well. However, Penfield's notion of the "mother's method" is entirely compatible with the current emphasis on interaction as a basis for language learning (see Cummins and Swain 1986).

The story has been very different in the evaluations of bilingual programs in the United States. Much of the research carried out was poorly designed (Baker \& de Kanter 1981), in part because of the much more complicated sociopolitical and educational context. For example, students were frequently exited from bilingual programs at very early stages (e.g. after one year) with the result that if students continued to perform poorly in English academic skills it was unclear whether this was due to premature exit to an all-English program or to the lack of effectiveness of bilingual education. Evaluations also tended to be atheoretical in that theory-based predictions regarding outcomes were seldom generated and tested. Thus, evaluators attempted to assess the "effectiveness" of bilingual education without any well-articulated hypotheses regarding how long it would take minority students to acquire age-appropriate levels of English academic skills and under what sociopolitical and instructional conditions (e.g. length and intensity of $\mathrm{Ll}$ instruction). 
The overall conclusion of immersion program evaluations is that the programs have been a resounding success and this has been effectively communicated to policy-makers, parents and educators. The result has been a huge increase in parental demand for French immersion programs which now have an enrolment of about 200,000 students and are offered in every Canadian province. Sociopolitical and administrative problems have emerged as a result of the increased demand for immersion programs (e.g. concerns by minority francophones of increased competition for bilingual jobs, layoff of teachers who do not speak French, etc.). However, these problems have not significantly slowed the momentum of immersion.

By contrast, bilingual programs in the United States are perceived much more equivocably by policy-makers and educators. This perception was reinforced by the research review conducted by Baker and de Kanter (1981) which concluded that transitional bilingual programs overall were not much more successful than English-only programs in promoting minority students' achievement. This review reflects the major problems of transitional bilingual education in that it is almost completely atheoretical and consequently ignores the consistent patterns that do emerge in the research data regarding transfer or interdependence of cognitive academic skills across languages.

In summary, the importance of generating and evaluating predictions from a coherent theory has been emphasized as a central, but frequently neglected, aspect of rational policy-making. Research findings become meaningful only when interpreted within a coherent theoretical framework. The contrast between the general acceptance and application of immersion program findings in Canada compared to the lack of acceptance of similar findings supporting exactly the same theoretical principles in the case of bilingual education in the United States illustrates the importance of inter-group power relations in research interpretation. Immersion programs are implemented by and serve the interests of the dominant group in Canada whereas bilingual programs in the United States confer power and status (e.g. through jobs) on previously dominated minorities and serve the interests of minorities rather than those of the dominant group. The demographic changes occurring in the United States with respect to the huge increase in the Hispanic population add to the urgency felt by many within the dominant group to restrict as much as possible the expanding power base of the minorities. This has been done by emasculating bilingual programs as much as possible by reducing the use of $\mathrm{L} 1$ and denying the value of these programs regardless of the research pointing to the contrary. 


\section{CONCLUSION}

The relationships between research, theory and policy have been illustrated with reference to current language/education planning situations in North American education. Two broad conclusions emerge: first, the central role of theory is minimally understood by many policy-makers. "Theory" is frequently dismissed as idle speculation ("it's just theory") by policy-makers who fail to appreciate that "facts" become interpretable only in the context of a coherent theory. For policy, theory is essentially the means for predicting outcomes under divergent conditions, and as such, is inseparable from the policy making process. It has been shown in the case studies reviewed that policy makers often operate with implicit theoretical assumptions that become immune from critical scrutiny as a result of the absence of a systematic process of validating/revising these theoretical assumptions in relation to research data.

The second general conclusion is that socio-political factors related to power and status relations between dominant and subordinate groups play a major role in the importance assigned to particular issues, the initiatives taken by policy-makers, the resources assigned to carry out research on particular topics, the conduct and interpretation of research, and the application of research to policy. There is no such thing as "pure research" on issues that reflect the power conflicts within society. Both language and education have traditionally served to stratify societal groups along class and ethnic lines and, in the past, research has legitimized this stratification; for example, by attributing school failure to inherent deficiencies of the minorities themselves, such as genetic inferiority, bilingualism, and cultural deprivation (see Hakuta 1986, for a review). Given the societal commitment to preserve the power relations between dominant and subordinate groups, funded research will naturally tend to serve the interests of the dominant group, as documented above. Researchers (and policy-makers) concerned with contributing to societal equity are faced with the delicate task of persuading representatives of the dominant group to fund research whose results are likely to challenge the power of the dominant group. Strategies for achieving this goal merit further discussion.

\section{REFERENCES}

Baker, K. A. \& de Kanter, A. A. (1981). Effectiveness of bilingual education: A review of the literature. Washington, D.C.: Office of Planning and Budget, U.S. Department of Education.

Burns, G. E. \& Olson, P. (1981). Implementation and politics in French immersion. Toronto: Ontario Institute for Studies in Education. 
Cummins, J. (1984). Bilingualism and special education: Issues in assessment and pedagogy. Clevedon, England: Multilingual Matters. Co-published in the United States by College-Hill Press, San Diego.

Cummins, J. \& Swain, M. (1986). Bilingualism in education: Issues in theory, research and policy. London: Longman.

Hakuta, K. (1986). Mirror of language: The debate on bilingualism. New York: Basic Books.

Lambert, W. E. \& Tucker, G. R. (1972). Bilingual education of children: The St. Lambert experiment. Rowley, Mass.: Newbury House.

Paulston, C. B. (1980). Bilingual education: Theory and research. Rowley, Mass.: Newbury House.

Penfield, W. (1965). Conditioning the uncommitted cortex for language learning. Brain, 88, 787-798.

Rees, O. (1981). Mother tongue and English teaching project. Bradford College.

Swain, M. \& Lapkin, S. (1982). Evaluating bilingual education. Clevedon, England: Multilingual Matters.

\section{THE AUTHOR}

Jim Cummins is an associate professor and director of the National Heritage Language Resource Unit at the Ontario Institute for Studies in Education. Among his publications are "Bilingualism and Special Education: Issues in Assessment and Pedagogy" (Multilingual Matters, 1984) and "Bilingualism in Education: Aspect, of Theory, Research and Policy" (1986 Longman, with Merrill Swain). 